\title{
The influence of vinegars on exposure of dentinal tubules: a SEM evaluation
}

\section{Influência de vinagres na exposição dos túbulos dentinários: avaliação em MEV}

\author{
Daniela Leal Zandim* \\ Fernanda Oliveira Bello Corrêa* \\ José Eduardo Cezar Sampaio** \\ Carlos Rossa Júnior***
}

\begin{abstract}
Dentin hypersensitivity is a common painful condition observed in clinics. Dietary habits have been much associated with its development and persistence during and following periodontal treatment. The aim of this in vitro study was to evaluate the influence of vinegars on the removal of smear layer and exposure of dentinal tubules. Extracted human teeth were submitted to manual scaling with Gracey curettes in order to remove the cementum as well as to form a smear layer. Dentin samples with $3 \mathrm{~mm}^{2}$ were obtained and distributed into six experimental groups: one control and five types of vinegars (alcohol, apple, rice, white wine and balsamic). Each group included two methods of vinegar application: topical and friction. After routine preparation for SEM analysis, photomicrographs were assessed by a calibrated and blind examiner using an appropriate index system. KruskalWallis test indicated a significant influence of vinegars on smear layer removal. There was a statistically significant difference between groups treated with apple, white and rice vinegars and the control group $(p<0.05)$. Nevertheless, Mann-Whitney test indicated that removal of smear layer did not vary with the method of application (topical versus friction) for any of the tested substances. We can conclude that the contact of vinegar may remove smear layer and expose dentinal tubules, regardless of the type of application. However, balsamic vinegar was associated with less removal of smear layer after both methods of application.
\end{abstract}

DESCRIPTORS: Dentin sensitivity; Diet; Smear layer.

RESUMO: A hipersensibilidade dentinária cervical é uma condição dolorosa muito comum nos consultórios. A dieta tem sido bastante associada ao seu aparecimento, assim como a sua persistência após o tratamento periodontal. O objetivo deste trabalho foi avaliar in vitro a influência dos vinagres na remoção de "smear layer" e exposição dos túbulos dentinários. Dentes de humanos foram instrumentados com curetas Gracey para a remoção do cemento e formação de "smear layer". Foram obtidas amostras de dentina com $3 \mathrm{~mm}^{2}$, divididas entre o grupo controle (água destilada) e cinco grupos de vinagre: branco, maçã, arroz, vinho branco e balsâmico. Cada grupo incluiu duas formas de aplicação da substância, tópica ou por fricção. Após o preparo para observação em MEV (microscopia eletrônica de varredura), as fotomicrografias foram avaliadas por um examinador previamente calibrado utilizando um indice apropriado. O teste de Kruskal-Wallis indicou influência significativa dos vinagres na remoção de "smear layer". Foi constatada uma diferença estatística significante entre os grupos maçã, branco e arroz e o grupo controle $(\mathrm{p}<0,05)$. O teste de Mann-Whitney, porém, indicou que a remoção de "smear layer" não variou para nenhuma das substâncias segundo a forma de aplicação. Conclui-se que os vinagres podem remover "smear layer" da superfície radicular e expor túbulos dentinários, não sendo influenciados pelo tipo de aplicação. Dentre os tipos de vinagres testados, o balsâmico esteve associado a menor remoção de "smear layer" após ambas as formas de aplicação.

DESCRITORES: Sensibilidade da dentina; Dieta; Camada de esfregaço.

\section{INTRODUCTION}

Studies on the prevalence of dentin hypersensitivity show that this condition is not an uncommon problem among the adult population. According to Azevedo ${ }^{4}$ (1994), six in ten patients have been reported to suffer from cervical dentin hypersensitivity; although Sobral et al. ${ }^{14}$ (1995) reported approximately one in six patients.

All tooth types may be affected, but canines and premolars in both jaws are the most frequently involved teeth. Nevertheless, dentin hypersensitiv-

\footnotetext{
* Graduate Students; **Adjunct Professor; ***PhD, Assistant Professor, Department of Diagnosis and Surgery, Division of Periodontics - School of Dentistry of Araraquara, São Paulo State University.
} 
Zandim DL, Corrêa FOB, Sampaio JEC, Rossa Júnior C. The influence of vinegars on exposure of dentinal tubules: a SEM evaluation. Braz Oral Res 2004;18(1):63-8.

ity is most commonly present at buccal cervical areas and does not have higher incidence in one gender ${ }^{2,14}$.

Dentin hypersensitivity has been described as an exaggerated sensitivity of exposed dentin in response to chemical, tactile or thermal stimuli ${ }^{16}$, where there is not any other form of dental defect or pathology ${ }^{15}$.

The hydrodynamic theory of Brännström is the currently accepted theory for transmission of stimuli in dentine. Fast fluid flow across the dentinal tubules activates the pain fibers at the pulpal wall and causes pain. The presence of open dentinal tubules seems to be a prerequisite for the occurrence of dentin sensitivity ${ }^{5}$.

According to Dowell, Addy ${ }^{9}$ (1983), exposure of cervical dentine can occur through the loss of covering enamel and/or gingival recession with loss of cementum.

Therefore, it is clear that there are a number of etiological factors that could potentially cause dentin hypersensitivity ${ }^{12}$. The influence of acid in the diet as a factor in dentin sensitivity was demonstrated in some studies. Evidence in vitro indicates that weak and strong acids, which are the content of food and beverage acids, can remove smear layer and expose dentinal tubules ${ }^{3,8}$. However, authors observed a negative association between the frequency of ingestion of specific acidic foods and beverages and the persistence of dentin sensitivity ${ }^{6}$. Findings suggest that dietary counseling should be part of the treatment offered to patients with these problems, particularly regarding the control of excessive consumption of acid 1,2,6,8 $^{\text {. }}$

The aim of this in vitro study was to evaluate, by using the scanning electron microscope (SEM), the influence of vinegars on the removal of smear layer and exposure of dentinal tubules.

\section{MATERIAL AND METHODS}

The study protocol was approved by the Research Ethics Committee of the School of Dentistry of Araraquara, São Paulo State University (UNESP).

Human teeth, recently-extracted for periodontal reasons, were used in the present study. High-speed diamond burs were used to remove the cementum from the cervical portion of the roots. Subsequently, teeth were instrumented with forty shaving strokes on each surface using Gracey curettes $5-6$ by the same examiner to form the smear layer. These roots were then reduced with a diamond disk to obtain dentin samples of $3 \times 3 \mathrm{~mm}$.
Five experimental groups were formed based on the type of tested vinegar (alcohol, apple, rice, white wine, balsamic). Distilled water was also included as a negative control and the $\mathrm{pH}$ of the vinegars was determined. Each group was then subdivided into two other groups based on the method of application, performed as follows ${ }^{8}$ :

- Topical: samples were immersed in the vinegar for five minutes and washed with a stream of tap water for fifteen seconds.

- Friction: samples were immersed in the vinegar for five minutes, brushed with a soft tooth brush for thirty seconds and washed with tap water for fifteen seconds.

Samples were submitted to routine processing for SEM analysis to obtain two photomicrographs of the centre of the sample, with magnifications of 750 and 1,500 X. These photomicrographs were subsequently assessed by an examiner previously calibrated and blind to the experimental groups, using the following index of smear layer removal:

- Grade 1 - Complete removal of smear layer and dentinal tubules open.

- Grade 2 - Partial removal of smear layer and dentinal tubules partially open.

- Grade 3 - Smear layer present on the root surface and only indication of opening of dentinal tubules.

- Grade 4 - Smear layer present on the root surface and total obliteration of dentinal tubules.

Considering that the data were obtained using an index representing a scoring system, non-parametric methods of analysis were applied. For the purpose of comparison among groups (different tested vinegars), these were considered to be independent with respect to the method of application of the substances (topical or friction). Thus, a non-parametric analysis of variance was used to compare the performance among groups according to each method of application. On the other hand, the Mann-Whitney test was applied to compare results between the two methods of application of each vinegar that was tested. A $5 \%$ confidence level was used and the calculations were performed with the software Statistica version 5.1 (Statsoft Inc., Tulsa, OK, USA).

\section{RESULTS}

Graph 1 represents the frequency of distribution of scores attributed to each group for the topical application. In this case, the Kruskal-Wallis test indicated a significant difference between 
Zandim DL, Corrêa FOB, Sampaio JEC, Rossa Júnior C. The influence of vinegars on exposure of dentinal tubules: a SEM evaluation. Braz Oral Res 2004;18(1):63-8.

substances $(\mathrm{H}=13.197, \mathrm{p}=0.021)$, and post hoc paired comparisons demonstrated that alcohol, apple and rice vinegars were significantly different from the negative control group ( $<0.05)$. These three vinegar groups presented an average rank lower than that of the negative control group, indicating greater removal of smear layer and opening of dentinal tubules. The balsamic and white wine groups were similar to the control group. The balsamic vinegar had a higher frequency of score 4 (Graph 1). In addition, from a comparison among vinegars, significant difference between balsamic and apple groups with topical application was verified.
Results for the active application of tested vinegar by friction were similar to those for topical application. Again, Kruskal-Wallis test indicated a significant difference among groups $(\mathrm{H}=12.015$, $\mathrm{p}=0.034)$, and post hoc paired comparisons showed that only the balsamic vinegar was not significantly different from the negative control group $(p>0.05)$. This group had a higher frequency of scores 3 and 4, as shown in Graph 2.

On the other hand, a comparison between the methods of application (topical versus friction) using the Mann-Whitney test did not show any significant differences (Graph 3).

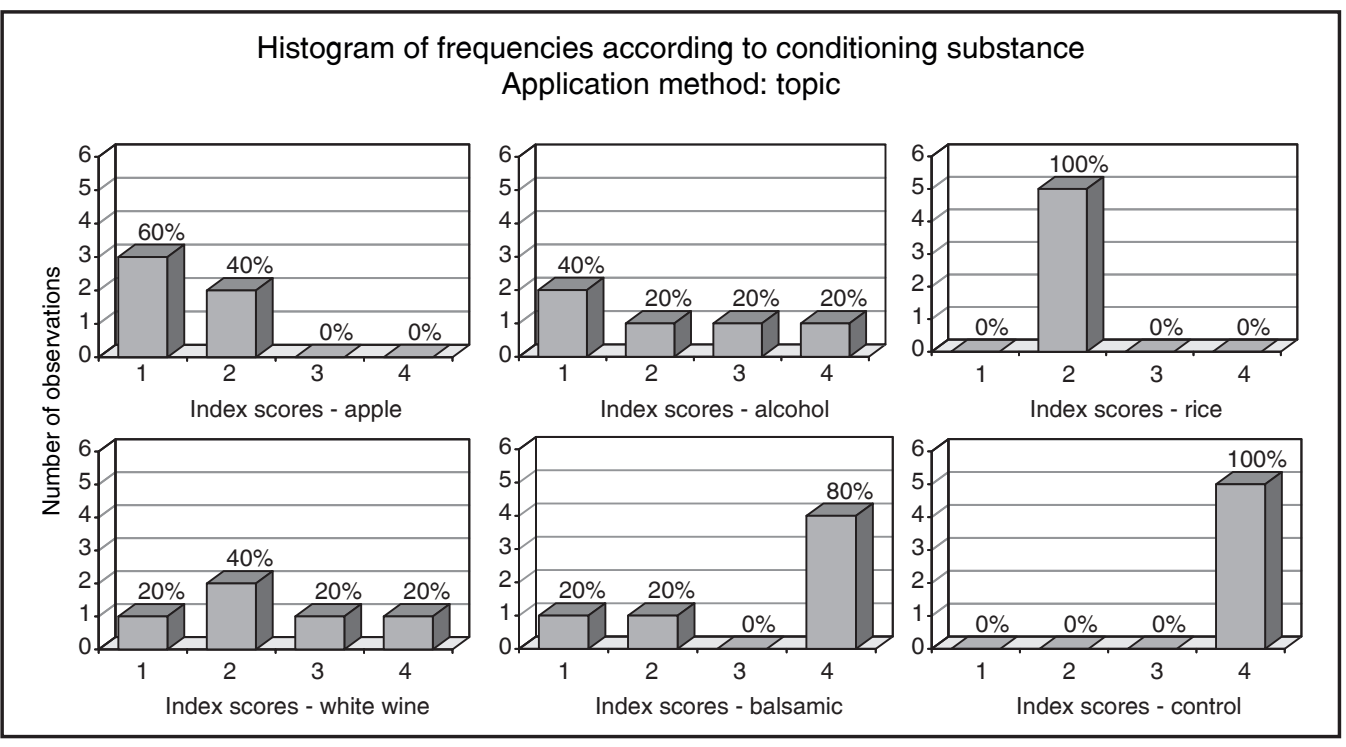

GRAPH 1 - Histogram showing the frequency distribution of scores attributed to samples treated topically with each of the substances tested.

Histogram of frequencies according to conditioning substance Application method: friction
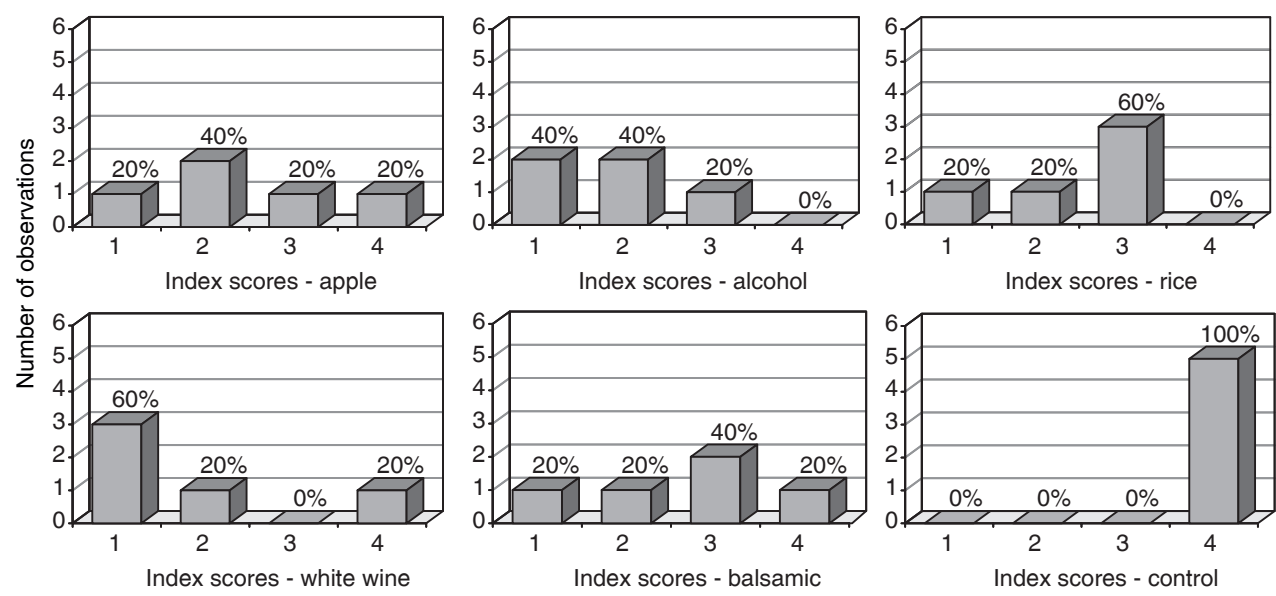

GRAPH 2 - Histogram showing the frequency distribution of scores attributed to samples treated actively (friction) with each of the substances tested. 
Zandim DL, Corrêa FOB, Sampaio JEC, Rossa Júnior C. The influence of vinegars on exposure of dentinal tubules: a SEM evaluation. Braz Oral Res 2004;18(1):63-8.

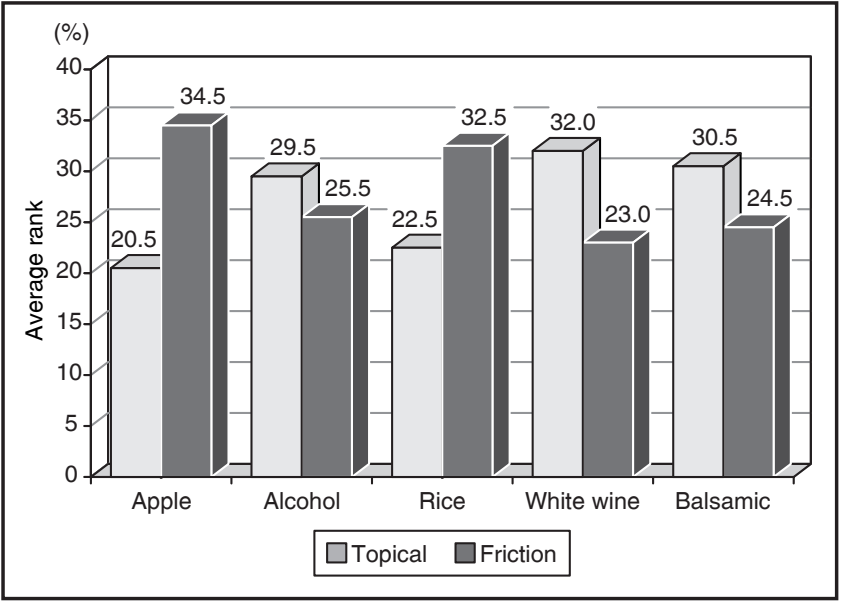

GRAPH 3 - Average rank of vinegars. Comparison between the methods of application (topical versus friction).

\section{DISCUSSION}

It is known that cervical dentin hypersensitivity has a multifactorial etiology, but the factors were not very clear. Prior studies demonstrated that one of the most important factors was the patient's diet. Thus, frequent ingestion of acidic foods and drinks can cause the loss of dental structure or remove smear layer, followed by sensitivity.

According to Pashley ${ }^{11}$ (1992), during root planing, although cementum and some dentin are removed, the dentinal tubules remain occluded by smear layer created during manipulation of the root surface. The smear layer would also restrict stimulus transmission across dentine, so teeth do not usually present hypersensitivity immediately or shortly after root scaling. With time, however, the loss of smear layer may be caused by toothbrushing, effects of dietary acids or both, thus allowing fluid movement in the dentinal tubules in response to stimuli.

It is evident in some studies that substances with lower $\mathrm{pH}$ can remove the smear layer and open dentinal tubules ${ }^{1,3,6,8}$, and it is important to check the $\mathrm{pH}$ to provide diet recommendations for patients who have dentin hypersensitivity. Corrêa et $a .^{7}$ (2002) determined the $\mathrm{pH}$ of some fruits, beverages, seasonings and the values found in the vinegars were similar to the types used in our study (Table 1).

Linkosalo, Markkanen ${ }^{10}$ (1985) researched the frequency and severity of erosions associated with diet of lactovegetarians. Erosive defects were found in $76.9 \%$ lactovegetarians, with different grades. In control groups, however, no erosion defects were
TABLE 1 - The $\mathrm{pH}$ of vinegars used in the study.

\begin{tabular}{l|c}
\hline \multicolumn{1}{c|}{ Vinegars } & $\mathrm{pH}$ \\
\hline Rice & 2.49 \\
\hline White wine & 2.45 \\
\hline Apple & 2.71 \\
\hline Alcohol & 2.79 \\
\hline Balsamic & 3.36 \\
\hline Distilled water (control) & 5.90 \\
\hline \hline
\end{tabular}

observed. Some differences were found between the dietary habits of lactovegetarians and those of the controls. The frequency of ingesting acid berries, vinegars or acid drinks and pickles was higher in lactovegetarians.

Since vinegar has low $\mathrm{pH}$ (Table 1) and was associated with dental erosion, we tested in vitro some types of vinegars to obtain the one that has the most reduced effect on dentin surface. The studies of Corrêa et al. ${ }^{8}$ (2002) and Prati et al. ${ }^{13}$ (2003) compared the effect of vinegar (acetic acid) and other acid substances on smear layer removal. Vinegar was able to remove smear layer, open dentinal tubules and increase dentin permeability in both studies. The same was observed in our study (Graphs 1 and 2).

Two methods of application were used in our study. Topical application to simulate the contact of cervical dentin exposure with acid foods and drinks, and the active application (friction) to check if toothbrush tends to exaggerate the erosive action of dietary acids (Graphs 1 and 2).

According to Absi et al. ${ }^{1}$ (1992), brushing in the presence of dietary acids enhanced smear layer removal and opening of tubules, for this reason toothbrushing should not take place at the same time of acidic food intake. However, Prati et al. ${ }^{13}$ (2003) observed in vitro that toothbrushing immediately after the exposure of dentin to acidic drinks reduced dentin permeability, creating a new fine and thin smear layer and the combination of toothbrushing and toothpaste created a new artificial smear layer (probably dentin debris and collagen mixed with toothpaste components) that is able to close tubules. These effects were not observed in our study. The Mann-Whitney test did not show any significant difference between the methods of application (topical versus friction) for any of the tested substances (Graph 3).

Based on the index system used in the current study, representing the degree of opening of 
Zandim DL, Corrêa FOB, Sampaio JEC, Rossa Júnior C. The influence of vinegars on exposure of dentinal tubules: a SEM evaluation. Braz Oral Res 2004;18(1):63-8.
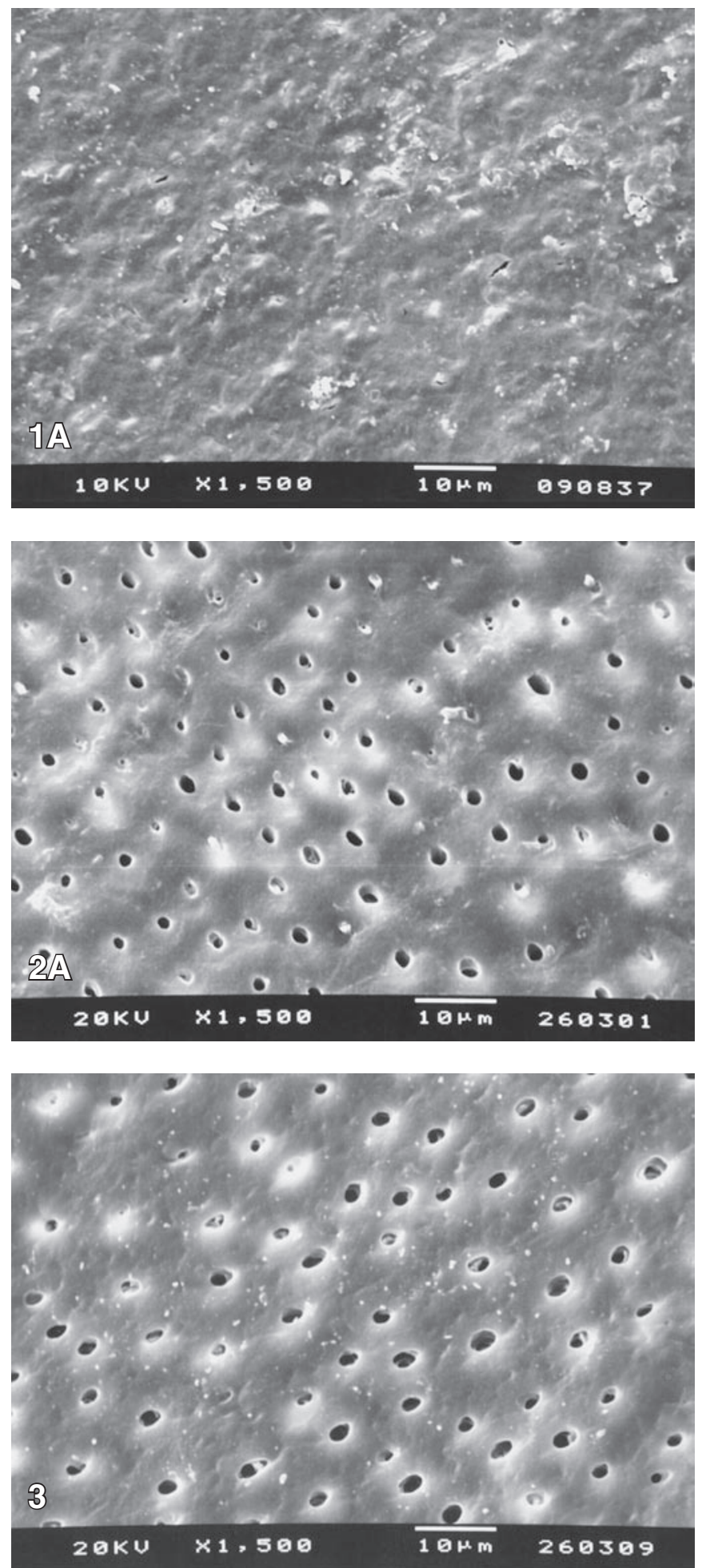

dentinal tubules, it was observed that after topical application and friction, the balsamic vinegar (Figure 1A) resulted predominantly in complete obliteration of dentinal tubules, similar to the control group (Figure 1B). This condition was also ob-
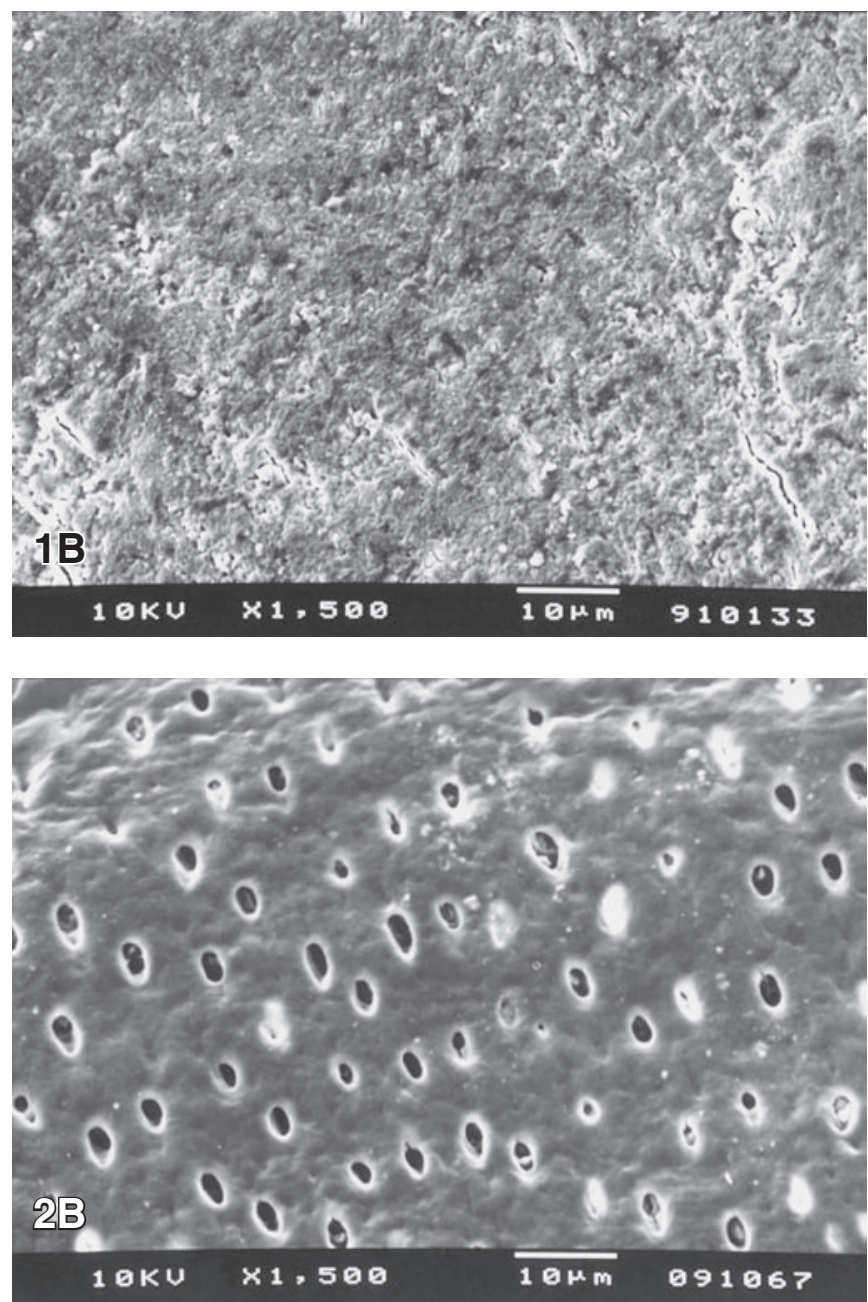

FIGURE 1 - Scanning electron micrographs showing the root surface covered with smear layer (1,500 X). A: balsamic vinegar (topical). B: negative control group (topical).

FIGURE 2 - Scanning electron micrographs showing opened dentinal tubules $(1,500 \mathrm{X})$. A: apple vinegar (topical). B: alcohol vinegar (topical).

FIGURE 3 - Scanning electron micrograph of white wine vinegar (friction), showing opened dentinal tubules $(1,500 \mathrm{X})$.

served in the study of Corrêa et al. ${ }^{8}$ (2002). After topical application, the rice vinegar was associated predominantly with dentinal tubules partially opened while apple (Figure 2A) and alcohol vinegar (Figure 2B) presented a much higher proportion 
Zandim DL, Corrêa FOB, Sampaio JEC, Rossa Júnior C. The influence of vinegars on exposure of dentinal tubules: a SEM evaluation. Braz Oral Res 2004;18(1):63-8.

of samples with complete opening of dentinal tubules. The same occurred with the white wine vinegar when the substances were applied by friction (Figure 3).

The findings of this study cannot necessarily be extrapolated to the clinical situation, but suggest that certain dietary factors could play a role in the etiology of dentin hypersensitivity. The oral environment is complex and a number of variables could modify the effects of acidic foods on dentin surface but, in view of these in vitro results, the

\section{REFERENCES}

1. Absi EG, Addy M, Adams D. Dentine hypersensitivity - the effect of toothbrushing and dietary compounds on dentine in vitro: a SEM study. J Oral Rehabil 1992;19:101-10.

2. Addy M. Clinical aspects of dentine hypersensitivity. Proc Finn Dent Soc 1992;88:22-30.

3. Addy M, Absi EG, Adams D. Dentine hypersensitivity. The effects in vitro of acids and dietary substances on root-planed and burred dentine. J Clin Periodontol 1987;14:274-9.

4. Azevedo VMNN. Avaliação clínica de pacientes portadores de lesões dentárias cervicais não cariosas relacionadas com alguns aspectos físicos, químicos e mecânicos da cavidade bucal [Tese de Doutorado]. Bauru: Faculdade de Odontologia da USP; 1994.

5. Brännström M. A hydrodinamic mechanism in the transmission of pain producing stimuli through the dentine. In: Anderson DJ, editor. Sensory mechanisms in dentine. London: Pergamon Press; 1962. p. 73-80.

6. Clark C, Woo G, Silver JG, Sweet D, Grisdale JC. The influence of frequent ingestion of acids in the diet on treatment for dentin sensitivity. J Periodontol Res 1990;56:11013.

7. Corrêa AM, Zukeran DYU, Corrêa FOB, Sampaio JEC. A influência do pH de frutas, bebidas e condimentos na hipersensibilidade dentinária cervical. Rev Robrac balsamic vinegar was the best to be consumed by patients with cervical dentin hypersensitivity.

\section{CONCLUSION}

This study showed that vinegars are able to remove smear layer and open dentinal tubules, regardless of the type of application. In comparison with the other types of vinegars, the balsamic one was associated with less removal of smear layer after topical application or friction.

8. Corrêa FOB, Rossa Júnior C, Sampaio JEC. Remoção da smear layer radicular através de bebidas da dieta. Estudo in vitro. JBE 2002;3:15-20.

9. Dowell PC, Addy M. Dentine hypersensitivity: a review. Etiology, symptoms and theories of pain production. J Clin Periodontol 1983;10:341-50.

10. Linkosalo E, Markkanen H. Dental erosions in relation to lactovegetarian diet. Scand J Dent Res 1985;93:436-41.

11. Pashley DH. Dentin permeability and dentin sensitivity. Proc Finn Dent Soc 1992;88:31-7.

12. Pereira JC. Hiperestesia dentinária: aspectos clínicos e formas de tratamento. Maxiodonto 1995;1:1-24.

13. Prati C, Montebugnoli L, Suppa P, Valdrè G, Mongiorgi R. Permeability and morphology of dentin after erosion induced by acidic drinks. J Periodontol 2003;74:428-36.

14. Sobral MAP, Carvalho RCR, Garone Netto N. Prevalência de hipersensibilidade dentinária cervical. Rev Odontol Univ São Paulo 1995;9:177-81.

15. Terezan MLF, Otero A. Hipersensibilidade dentinária: perspectivas atuais de tratamento. Rev Bras Odontol 2001;58:82-6.

16. Vale IS, Bramante AS. Hipersensibilidade dentinária: diagnóstico e tratamento. Rev Odontol Univ São Paulo 1997;11:207-13. 